\title{
Pengaruh Promosi dan Kualitas Pelayanan Terhadap Kepuasan Pelanggan Grab di Kota Denpasar
}

\author{
Dewa Gede Wahyu Santosa ${ }^{1}$ \\ I.A Mashyuni ${ }^{2}$ \\ ${ }^{1,2}$ Fakultas Ekonomi, Bisnis dan Pariwisata Universitas Hindu Indonesia \\ Email : dewawahyusantosa70008@gmail.com
}

\begin{tabular}{|l|l|l|}
\hline Diterima: 6 Desember & Direvisi: 12 Desember & Disetujui: 24 Desember 2020 \\
\hline
\end{tabular}

\begin{abstract}
Customer satisfaction is a feeling of pleasure or satisfaction from customers that arise after using or consuming a product / service. The purpose of this study is to determine how promotion and quality influence Grab customer satisfaction in Denpasar City partially and simultaneously. This research was conducted in the city of Denpasar. The number of samples taken was 100 respondents. Data collection techniques are observation, interviews, documentation, literature and questionnaires. The data analysis technique used is multiple linear regression. The test results show that the effect of promotion and service quality on Grab service satisfaction in Denpasar City is partially and simultaneously significant.
\end{abstract}

Keywords: promotion, service quality, customer satisfaction

\begin{abstract}
ABSTRAK
Kepuasan pelanggan adalah sebuah perasaan senang atau puas pelanggan yang muncul setelah menggunakan atau mengkonsumsi sebuah produk/jasa.Tujuan penelitian ini adalah untuk mengetahui bagaimana pengaruh promosi dan kualitas terhadap kepuasan pelanggan Grab di Kota Denpasar secara parsial dan simultan. Penelitian ini dilakukan di kota Denpasar. Jumlah sampel yang diambil adalah sebanyak 100 respoden. Teknik pengumpulan datanya adalah observasi, wawancara, dokumentasi, kepustakaan dan angket. Teknik analisi data yang digunakan uji regresi linier berganda. Hasil pengujian menunjukkan pengaruh promosi dan kualitas pelayanan terhadap kepuasan pelayanan Grab di Kota Denpasar adalah signifikan secara parsial dan simultan.
\end{abstract}

Kata kunci : promosi, kualitas pelayanan, kepuasan pelanggan

\section{Pendahuluan}

Pesatnya perkembangan teknologi kini telah merambah ke berbagai bidang termasuk transportasi dengan munculnya perusahaan-perusahaan transportasi berbasis aplikasi smartphone dengan menyediakan aplikasi pada smartphone berbasis andorid maupun ios. Di Indonesia saat ini terdapat beberapa pelaku bisnis transportasi online, namun dua yang terbesar adalah Gojek dan Grab yang merupakan pelopor dalam bisnis transportasi online. Kedua perusahaan transportasi berbasis online yang kian melekat dibenak masyarakat Indonesia. 
Grab memiliki produk jasa seperti jasa angkutan menggunakan sepeda motor dan mobil, dan grabfood untuk pengantaran makanan, grabexpress untuk pengantaran barang, pulsa/token sebagai transaksi pembelian pulsa provider dan listrik, yang terbaru adalah eScooter, selanjutnya ada grab ticket yakni untuk mempermudah pembeliian tiket bioskop, lalu grab hotel untuk mempermudah pelanggan dalam booking penginapan, dan yang terakhir ada layanan grab video yang sangat berguna bagi pelanggan yang ingin streaming video. Persaingan yang semakin ketat membuat Grab harus memperhatikan hal tersebut salah satunya dengan memperhatikan kepuasan yang diberikan kepada pelanggan. Grab harus mengetahui kebutuhan dan keinginan konsumen sehingga nantinya diharapkan dapat menciptakan kepuasan pelanggan.

Kepuasan pelanggan adalah perasaan yang menyenangkan yang didapat saat mendapatkan sesuatu atau sesuatu yang diinginkan terjadi (Tjiptono, 2008:292). Untuk menciptakan kepuasan tersebut perusahaan harus memperhatikan faktor-faktor kepuasan pelanggan diantaranya promosi dan kualitas pelayanan. (Irawan 2009). Promosi adalah semua kegiatan perusahaan produsen untuk meningkatkan mutu produknya dan membujuk/merayu konsumen agar membeli produknya (Ginting, 2012:10). Beberapa penelitian terdahulu telah membuktikan bahwa promosi berpengaruh positif dan signifikan terhadap kepuasan diantaranya dalam penelitian Juniantara dan Sukawati (2018), Sentiana (2018), Tjahjaningsih (2013) dan Handoko (2017) yang menyatakan bahwa promosi berpengaruh positif dan signifikan terhadap kepuasan pelanggan pada setiap penelitian masing-masing.

Selain promosi perusahaan juga harus memperhatikan kualitas pelayanan yang diberikan untuk para pelanggannya. Menurut Kotler (2000:25) kualitas pelayanan merupakan totalitas dari bentuk karakteristik barang dan jasa yang menunjukkan kemampuannya untuk memuaskan kebutuhan pelanggan, baik yang Nampak jelas maupun yang tersembunyi. Pengaruh kualitas pelayanan terhadap kepuasan telah dibuktikan sebelumnya oleh Juniantara dan Sukawati (2018), Wijaya (2017), Adnyana dan Suprapti (2018), serta Handoko (2017) yang membuktikan kualitas pelayanan berpengaruh positif dan signifikan terhadap kepuasan pelanggan.

Ketatnya persaingan dalam industri transportasi online yang kini dihadapi oleh Grab, meskipun hanya terdapat dua pemain utama dalam industri ini yaitu dengan Gojek sebagai pesaing utama maka sudah sepantasnya Grab memperhatikan bagaimana promosi 
yang ditawarkan dan juga kualitas pelayanan yang diberikan mampu menciptakan kepuasan kepada pelanggannya. Tujuan penelitian ini adalah (1) mengetahui pengaruh promosi terhadap kepuasan pelanggan pengguna Jasa Transportasi Online Grab di Denpasar, (2) untuk mengetahui dan pengaruh kualitas pelayanan terhadap kepuasan pelanggan pengguna Jasa Transportasi Online Grab di Denpasar, dan (3) untuk mengetahui pengaruh promosi dan kualitas pelayanan terhadap kepuasan pelanggan pengguna Jasa Transportasi Online Grab di Denpasar.

\section{Telaah Literatur Dan Hipotesis}

\section{Promosi}

Promosi adalah kegiatan perusahaan untuk meningkatkan mutu produknya dan membujuk/merayu konsumen agar membeli produknya (Ginting, 2012:10). Menurut Kismono (2001: 374), perusahaan perlu menetapkan tujuan promosi secara lebih luas.

\section{Kualitas Pelayanan}

Menurut Kotler (2000:25) kualitas pelayanan merupakan totalitas dari bentuk karakteristik barang dan jasa yang menunjukkan kemampuannya untuk memuaskan kebutuhan pelanggan, baik yang Nampak jelas maupun yang tersembunyi. Menurut Rangkuti (2006:29) dimensi kualitas pelayanan terdiri atas bukti fisik, kehandalan, ketanggapan, jaminan, dan empati.

\section{Kepuasan Pelanggan}

Kepuasan adalah perasaan senang atau kecewa seseorang yang berasal dari perbandingan antara kesannya terhadap kinerja (atau hasil) suatu produk dan harapanharapannya (Kotler, 2000). Kepuasan pelanggan didefinisikan sebagai evaluasi purnakonsumsi (post consumption) dimana alternatif yang dipilih paling tidak memenuhi atau melampaui harapan. (Engel, al., 1990).

\section{Hipotesis}

H1 : Diduga promosi berpengaruh positif dan signifikan terhadap kepuasaan pelanggan Jasa Transportasi Online Grab diDenpasar.

H2 : Diduga Kualitas Pelayanan berpengaruh positif dan signifikan terhadap kepuasan pelanggan JasaTransportasi Online Grab diDenpasar.

H3 : Diduga Promosi dan Kualitas Pelayanan berpengaruh positif dan signifikan terhadap kepuasan pelanggan Jasa Transportasi Online Grab di Denpasar. 


\section{Metode Penelitian}

Variabel dalam penelitian ini yaitu promosi dan kualitas pelayanan apabila dihubungkan dan diidentifikasi pengaruhnya, maka dapat diduga bahwa terdapat hubungan yang simultan maupun parsial atau masing-masing antara promosi dan kualitas pelayanan mampu mempengaruhi kepuasan pelanggan. Sehingga dapat digambarkan kerangka penelitian ini seperti pada gambar berikut ini.

\section{Gambar 1. Kerangka Berpikir}

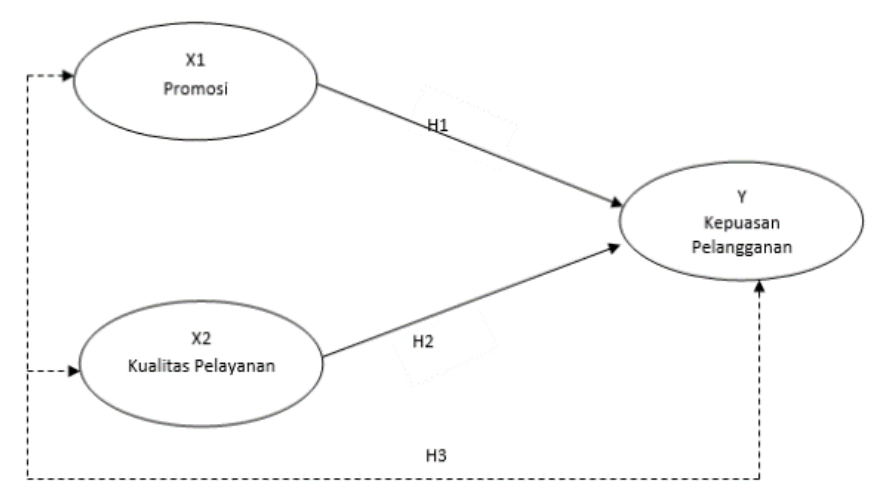

Populasi dalam penelitian ini adalah masyarakat Kota Denpasar dengan usia minimal 17 tahun yang pernah menggunakan layanan ojek online Grab. Dalam penelitian ini sampel yang diambil menggunakan teknik pengambilan sampel purposive sampling, dengan sampel 5 sampai 10 kali jumlah indikator sehingga kriteria ini menghasilkan rentang $12 \times(5-10)=60-120$ dan berdasarkan batasan tersebut maka penelitian ini mengambil sampel sebanyak 100 responden. Pada tahap pengumpulan data dilakukan dengan menggunakan metode observasi, wawancara, dokumentasi, dan kuisioner. Skala pengukuran yang digunakan adalah Skala Likert dengan lima pilihan jawaban yang terdiri atas jawaban sangat tidak setuju diberi nilai 1, jawaban tidak setuju diberi nilai 2, jawaban cukup setuju diberi nilai 3, jawaban setuju diberi nilai 4, dan jawaban sangat setuju diberi nilai 5. Teknik analisis data yang digunakan adalah regresi linear berganda.

\section{Hasil Dan Pembahasan}

\section{Uji Instrumen Penelitian}

Tabel 1 menunjukkan bahwa seluruh koefisien korelasi dari indikator variabel yang diuji nilainya lebih besar dari 0,30. Hasil tersebut menunjukkan bahwa seluruh indikator dalam variabel promosi, kualitas pelayanan dan kepuasan pelanggan yang terdapat pada penelitian ini terbukti valid. Berdasarkan nilai Cronbach's Alpha yang nilainya melebihi 0,60 maka dapat dikatakan bahwa instrumen penelitian ini adalah reliabel. 
Tabel 1. Hasil uji Validitas dan Reliabilitas

\begin{tabular}{|c|c|c|c|c|c|}
\hline \multirow[b]{2}{*}{ Variabel } & \multirow[b]{2}{*}{$\begin{array}{c}\text { Item } \\
\text { Pernyataan }\end{array}$} & \multicolumn{2}{|c|}{ Validitas } & \multicolumn{2}{|c|}{ Reliabilitas } \\
\hline & & $\begin{array}{c}\text { Koefisien } \\
\text { korelasi }\end{array}$ & Ket. & $\begin{array}{c}\text { Cronbach's } \\
\text { Alpha }\end{array}$ & Ket. \\
\hline \multirow{8}{*}{ Promosi } & $\mathrm{X} 1.1$ & 0,892 & Valid & \multirow{8}{*}{0,953} & \multirow{8}{*}{ Reliabel } \\
\hline & $\mathrm{X} 1.2$ & 0,814 & Valid & & \\
\hline & $\mathrm{X} 1.3$ & 0,853 & Valid & & \\
\hline & $\mathrm{X} 1.4$ & 0,88 & Valid & & \\
\hline & $\mathrm{X} 1.5$ & 0,894 & Valid & & \\
\hline & X1.6 & 0,836 & Valid & & \\
\hline & $\mathrm{X} 1.7$ & 0,884 & Valid & & \\
\hline & $\mathrm{X} 1.8$ & 0,883 & Valid & & \\
\hline \multirow{12}{*}{$\begin{array}{l}\text { Kualitas } \\
\text { pelayanan }\end{array}$} & $\mathrm{X} 2.1$ & 0,841 & Valid & \multirow{12}{*}{0,965} & \multirow{12}{*}{ Reliabel } \\
\hline & $\mathrm{X} 2.2$ & 0,867 & Valid & & \\
\hline & $\mathrm{X} 2.3$ & 0,881 & Valid & & \\
\hline & $\mathrm{X} 2.4$ & 0,876 & Valid & & \\
\hline & $\mathrm{X} 2.5$ & 0,838 & Valid & & \\
\hline & X2.6 & 0,866 & Valid & & \\
\hline & $\mathrm{X} 2.7$ & 0,868 & Valid & & \\
\hline & $\mathrm{X} 2.8$ & 0,843 & Valid & & \\
\hline & X2.9 & 0,882 & Valid & & \\
\hline & $\mathrm{X} 2.10$ & 0,837 & Valid & & \\
\hline & $\mathrm{X} 2.11$ & 0,863 & Valid & & \\
\hline & $\mathrm{X} 2.12$ & 0,882 & Valid & & \\
\hline \multirow{10}{*}{$\begin{array}{l}\text { Kepuasan } \\
\text { pelanggan }\end{array}$} & Y1 & 0,926 & Valid & \multirow{10}{*}{0,987} & \multirow{10}{*}{ Reliabel } \\
\hline & Y2 & 0,967 & Valid & & \\
\hline & Y3 & 0,944 & Valid & & \\
\hline & Y4 & 0,924 & Valid & & \\
\hline & Y5 & 0,974 & Valid & & \\
\hline & Y6 & 0,923 & Valid & & \\
\hline & Y7 & 0,974 & Valid & & \\
\hline & Y8 & 0,959 & Valid & & \\
\hline & Y9 & 0,91 & Valid & & \\
\hline & $\mathrm{Y} 10$ & 0,976 & Valid & & \\
\hline
\end{tabular}

Sumber : data diolah, 2020

\section{Karakteristik Responden}

Tabel 2. Karakteristik Responden

\begin{tabular}{clcc}
\hline Kategori & \multicolumn{1}{c}{ Pilihan } & $\begin{array}{c}\text { Jumlah } \\
\text { (orang) }\end{array}$ & Persentase (\%) \\
\hline \multirow{3}{*}{ Jenis Kelamin } & Laki- Laki & 54 & 54 \\
& Perempuan & 46 & 46 \\
& Jumlah & 100 & 100 \\
\hline \multirow{4}{*}{ Usia } & 18-24 Tahun & 33 & 33 \\
& 25-34 Tahun & 32 & 32 \\
& 35-40 Tahun & 19 & 19 \\
& >40Tahun & 16 & 16 \\
& Jumlah & 100 & 100 \\
\hline \multirow{3}{*}{ Pendidikan } & SMA & 46 & 46 \\
terakhir & Diploma & 24 & 24 \\
& S1 & 30 & 30 \\
& Jumlah & 100 & 100 \\
\hline
\end{tabular}

Sumber : data diolah, 2020 
Berdasarkan hasil penelitian yang dilakukan terhadap pelanggan Pada Jasa Transportasi Online Grab dapat diketahui karakteristik respondennya meliputi jenis kelamin, usia dan pendidikan terakhir.

Berdasarkan jenis kelamin, jenis kelamin laki-laki mendominasi dalam penelitian ini dengan persentase sebesar 54 persen. Jika di lihat dari usia, yang memiliki usia 18-24 tahun mendominasi dengan presentase sebesar 33 persen. Jika di lihat dari tingkat pendidikan yang memiliki tingkat pendiddikan terakhir SMA yang mendominasi dengan persentase sebesar 46 persen.

\section{Deskripsi Variabel Penelitian}

Berdasarkan Tabel 3 diketahui persepsi responden mengenai variabel Promosi memiliki rata-rata total sebesar 3,34 yang termasuk kriteria cukup. Rata-rata terendah adalah pernyataan "Grab memberikan reward untuk pelanggan setia sebagai bentuk apresiasi berupa pelayanan gratis" diperoleh nilai rata-rata sebesar 3,24 yang masuk kriteria cukup baik, sedangkan rata-rata tertinggi adalah pernyataan "Grab mempromosikan potongan harga diberbagai social media..”, diperoleh nilai rata-rata sebesar 3,47 yang masuk kriteriabaik.

Tabel 3. Jawaban Responden Tentang Promosi

\begin{tabular}{|c|c|c|c|c|c|c|c|}
\hline \multirow{2}{*}{ Pernyataan } & \multicolumn{5}{|c|}{ Jawaban Responden } & \multirow{2}{*}{$\begin{array}{l}\text { Rata- } \\
\text { rata }\end{array}$} & \multirow{2}{*}{ Kriteria } \\
\hline & 1 & 2 & 3 & 4 & 5 & & \\
\hline Grab sering memberi potongan harga. & 1 & 22 & 29 & 36 & 12 & 3,36 & Cukup Baik \\
\hline $\begin{array}{l}\text { Grab mempromosikan potongan harga } \\
\text { diberbagai social media. }\end{array}$ & 4 & 4 & 50 & 25 & 17 & 3,47 & Baik \\
\hline $\begin{array}{l}\text { Potongan harga yang ditetapkan menggunakan } \\
\text { ovo (uang elektronik) sangat menguntungkan } \\
\text { konsumen }\end{array}$ & 5 & 3 & 61 & 19 & 12 & 3,3 & Cukup Baik \\
\hline $\begin{array}{l}\text { Beragam voucher belanja ditawarkan Grab } \\
\text { dengan beberapa ketentuan yang cenderung } \\
\text { mudah. }\end{array}$ & 2 & 20 & 30 & 42 & 6 & 3,3 & Cukup Baik \\
\hline Voucher yang ditawarkan Grab bervariatif. & 1 & 27 & 24 & 36 & 12 & 3,31 & Cukup Baik \\
\hline $\begin{array}{l}\text { Voucher yang ditawarkan Grab mampu } \\
\text { bersaing dengan ojek online lainnya. }\end{array}$ & 5 & 6 & 47 & 25 & 17 & 3,43 & Baik \\
\hline $\begin{array}{l}\text { Grab memberikan reward untuk pelanggan } \\
\text { setia sebagai bentuk apresiasi berupa pelayanan } \\
\text { gratis. }\end{array}$ & 7 & 5 & 57 & 19 & 12 & 3,24 & Cukup Baik \\
\hline \multirow[t]{2}{*}{$\begin{array}{l}\text { Reward yang diberikan Grab bisa ditukarkan } \\
\text { dengan mudah tanpa syarat dan ketentuan. }\end{array}$} & 3 & 20 & 29 & 42 & 6 & 3,28 & Cukup Baik \\
\hline & & & & & & 3,34 & Cukup Baik \\
\hline
\end{tabular}

Sumber : data diolah, 2020

Berdasarkan Tabel 4 diketahui persepsi responden mengenai variabel Kualitas pelayananmemiliki rata-rata total sebesar 3,36 yang termasuk kriteria cukup. Rata-rata terendah adalah pernyataan " Pihak kantor Grab sigap dalam melayani keluhan atau 
permasalahan yang dihadapi" diperoleh nilai rata-rata sebesar 3,10 yang masuk kriteria cukup baik, sedangkan rata-rata tertinggi adalah pernyataan "Driver Grab selalu membawa helm untuk pelanggannya demi keselamatan bersama." diperoleh nilai rata-rata sebesar 3,70 yang masuk kriteria baik

Tabel 4. Jawaban Responden Tentang Kualitas Pelayanan

\begin{tabular}{|c|c|c|c|c|c|c|c|}
\hline \multirow{2}{*}{ Pernyataan } & \multicolumn{5}{|c|}{ Jawaban Responden } & \multirow{2}{*}{$\begin{array}{c}\text { Rata- } \\
\text { rata }\end{array}$} & \multirow{2}{*}{ Kriteria } \\
\hline & 1 & 2 & 3 & 4 & 5 & & \\
\hline $\begin{array}{l}\text { Dengan memesan jasa Grab segala aktifitas } \\
\text { menjadi lebih mudah. }\end{array}$ & 1 & 13 & 67 & 14 & 5 & 3.09 & Cukup Baik \\
\hline $\begin{array}{l}\text { Bertransportasi dengan menggunakan Grab } \\
\text { cepat sampai di lokasi tujuan yang } \\
\text { diinginkan. }\end{array}$ & 4 & 6 & 48 & 26 & 16 & 3.44 & Baik \\
\hline $\begin{array}{l}\text { Pihak kantor Grab sigap dalam melayani } \\
\text { keluhan atau permasalahan yang dihadapi } \\
\text { konsumen saat menggunakan aplikasi } \\
\text { transportasi online Grab. }\end{array}$ & 3 & 7 & 72 & 13 & 5 & 3.10 & Cukup Baik \\
\hline $\begin{array}{l}\text { Aplikasi Grab telah dilengkapi dengan } \\
\text { layanan pembatalan jika terjadi kesalahan } \\
\text { pada pesanan. }\end{array}$ & 7 & 3 & 28 & 42 & 20 & 3.65 & Baik \\
\hline $\begin{array}{l}\text { Grab mengutamakan kenyamanan dan } \\
\text { keselamatan konsumennya. }\end{array}$ & 8 & 5 & 35 & 36 & 16 & 3.47 & Baik \\
\hline $\begin{array}{l}\text { Driver Grab selalu berkelakuan baik dan } \\
\text { sopan terhadap pelanggan. }\end{array}$ & 4 & 6 & 50 & 24 & 16 & 3.42 & Cukup Baik \\
\hline $\begin{array}{l}\text { Aplikasi Grab dilengkapi layanan } \\
\text { pengembalian uang jika tempat atau restorant } \\
\text { yang dituju tutup. }\end{array}$ & 3 & 7 & 72 & 11 & 7 & 3.12 & Cukup Baik \\
\hline $\begin{array}{l}\text { Aplikasi transportasi Grab memberi akses } \\
\text { komunikasi yang lancar untuk driver dan } \\
\text { pelanggan. }\end{array}$ & 1 & 13 & 66 & 13 & 7 & 3.12 & Cukup Baik \\
\hline $\begin{array}{l}\text { Driver Grab selalu membawa helm untuk } \\
\text { pelanggannya demi keselamatan bersama. }\end{array}$ & 7 & 3 & 25 & 43 & 22 & 3.70 & Baik \\
\hline $\begin{array}{l}\text { Driver grab selalu menawarkan jas hujan } \\
\text { ketika cuaca sedang hujan. }\end{array}$ & 8 & 5 & 29 & 39 & 19 & 3.56 & Baik \\
\hline $\begin{array}{l}\text { Driver Grab menggunakan kendaraan dengan } \\
\text { surat-surat lengkap. }\end{array}$ & 4 & 6 & 47 & 26 & 17 & 3.46 & Baik \\
\hline $\begin{array}{l}\text { Driver Grab berpenampilan rapi dengan } \\
\text { menggunakan atribut lengkap sesuai aturan } \\
\text { Grab. }\end{array}$ & 3 & 7 & 70 & 13 & 7 & 3.14 & Cukup Baik \\
\hline & & & & & & 3,36 & Cukup Baik \\
\hline
\end{tabular}

Sumber : data diolah, 2020

Berdasarkan Tabel 5 diketahui persepsi responden mengenai variabel Kepuasan pelanggan memiliki rata-rata total sebesar 3,24 yang termasuk dalam kriteria cukup. Ratarata terendah adalah pernyataan "Saya memberikan peringkat yang baik untuk pelayanan driver Grab." diperoleh nilai rata-rata sebesar 3,10 yang masuk dalam kriteria cukup baik, sedangkan rata-rata tertinggi adalah pernyataan "Saya puas atas jasa Grab sebagai transportasi online..”, diperoleh nilai rata-rata sebesar 3,48 yang masuk dalam kriteria baik. 
Tabel 5. Jawaban Responden Tentang Kepuasan Pelanggan

\begin{tabular}{|c|c|c|c|c|c|c|c|}
\hline \multirow{2}{*}{ Pernyataan } & \multicolumn{5}{|c|}{ Jawaban Responden } & \multirow{2}{*}{$\begin{array}{c}\text { Rata- } \\
\text { rata }\end{array}$} & \multirow{2}{*}{ Kriteria } \\
\hline & 1 & 2 & 3 & 4 & 5 & & \\
\hline $\begin{array}{l}\text { Saya puas atas jasa Grab sebagai transportasi } \\
\text { online. }\end{array}$ & 7 & 12 & 27 & 34 & 20 & 3,48 & Baik \\
\hline $\begin{array}{l}\text { Saya merasa menggunakan ojek online Grab } \\
\text { sesuai dengan kebutuhan saya. }\end{array}$ & 10 & 10 & 42 & 27 & 11 & 3,19 & Cukup Baik \\
\hline $\begin{array}{l}\text { Segala bentuk pelayanan tambahan yang } \\
\text { ditawarkan grab seperti grabfood, grabcar dll } \\
\text { membuat saya puas. }\end{array}$ & 7 & 14 & 40 & 28 & 11 & 3,22 & Cukup Baik \\
\hline $\begin{array}{l}\text { Jika ingin menggunakan transportasi online, } \\
\text { saya pasti memilih Grab. }\end{array}$ & 3 & 16 & 43 & 25 & 13 & 3,29 & Cukup Baik \\
\hline $\begin{array}{l}\text { Karena keuntungan yang ditawarkan Grab, } \\
\text { saya berlangganan Grab. }\end{array}$ & 10 & 14 & 39 & 28 & 9 & 3,12 & Cukup Baik \\
\hline $\begin{array}{l}\text { Saya selalu berniat memesan Grab karena } \\
\text { banyaknya tawaran promo yang } \\
\text { diinformasikan pada Inbox. }\end{array}$ & 7 & 12 & 29 & 34 & 18 & 3,44 & Baik \\
\hline $\begin{array}{l}\text { Saya akan merekomendasikan tentang } \\
\text { transportasi online Grab kepada teman-teman } \\
\text { dan kerabat saya. }\end{array}$ & 10 & 10 & 43 & 28 & 9 & 3,16 & Cukup Baik \\
\hline $\begin{array}{l}\text { Jika sedang ngumpul bareng temen, saya } \\
\text { selalu memesan Grabfood yang diikuti teman- } \\
\text { teman saya. }\end{array}$ & 7 & 15 & 41 & 28 & 9 & 3,17 & Cukup Baik \\
\hline $\begin{array}{l}\text { Saya selalu memberi ulasan yang baik setelah } \\
\text { menggunakan Grab. }\end{array}$ & 3 & 16 & 47 & 23 & 11 & 3,23 & Cukup Baik \\
\hline $\begin{array}{l}\text { Saya memberikan peringkat yang baik untuk } \\
\text { pelayanan driver Grab. }\end{array}$ & 10 & 14 & 41 & 26 & 9 & 3,1 & Cukup Baik \\
\hline & & & & & & 3,24 & Cukup Baik \\
\hline
\end{tabular}

Sumber : data diolah, 2020

\section{Uji Asumsi Klasik}

Tabel 6 menunjukkan bahwa besarnya nilai Kolmogorov-Smirnov adalah sebesar 0,922. Nilai Kolmogorov-Smirnov tersebut lebih besar dibandingkan dengan nilai alpha sebesar 0,05 maka mengindikasikan bahwa data yang digunakan pada penelitian ini terdistribusi normal, sehingga dapat disimpulkan bahwa model memenuhi asumsi normalitas.

Tabel 6. Hasil Uji Normalitas One-Sample Kolmogorov-Smirnov Test

\begin{tabular}{llr}
\hline & & $\begin{array}{c}\text { Unstandardized } \\
\text { Residual }\end{array}$ \\
\hline $\mathrm{N}$ & Mean & 100 \\
Normal Parameters ${ }^{\mathrm{a}, \mathrm{b}}$ & Std. Deviation & .000 \\
& Absolute & .72225010 \\
Most Extreme Differences & Positive & .055 \\
& Negative & .051 \\
Kolmogorov-Smirnov Z & & -.055 \\
Asymp. Sig. (2-tailed) & & .551 \\
\hline
\end{tabular}

Sumber : data diolah, 2020 
Berdasarkan Tabel 7 ditunjukkan bahwa tidak terdapat variabel bebas yang memiliki nilai tolerance kurang dari 0,10 dan juga tidak ada variabel bebas yang memiliki nilai VIF lebih dari 10. Maka dari pada itu model regresi bebas dari gejala multikoleniaritas.

\begin{tabular}{|c|c|c|c|}
\hline \multicolumn{4}{|c|}{$\begin{array}{c}\text { Tabel 7. Hasil Uji Multikolinearitas } \\
\text { Coefficients }^{\mathrm{a}}\end{array}$} \\
\hline \multirow{2}{*}{\multicolumn{2}{|c|}{ Model }} & \multicolumn{2}{|c|}{ Collinearity Statistics } \\
\hline & & Tolerance & VIF \\
\hline \multirow{2}{*}{1} & Promosi & .761 & 1.314 \\
\hline & Kualitas pelayanan & .761 & 1.314 \\
\hline
\end{tabular}

Berdasarkan Tabel 8, ditunjukkan bahwa masing-masing model memiliki nilai signifikansi lebih besar dari 5\% sehingga variabel bebas yang digunakan pada penelitian ini tidak berpengaruh secara signifikan terhadap variabel terikatnya yaitu absolute error, maka dari itu, penelitian ini bebas dari gejala heteroskedastisitas.

Tabel 8. Hasil uji Heteroskedastisitas Coefficients $^{\mathrm{a}}$

\begin{tabular}{|c|c|c|c|c|c|c|}
\hline \multicolumn{7}{|c|}{ Coefficients $^{a}$} \\
\hline \multirow{2}{*}{\multicolumn{2}{|c|}{ Model }} & \multicolumn{2}{|c|}{$\begin{array}{l}\text { Unstandardized } \\
\text { Coefficients }\end{array}$} & \multirow{2}{*}{$\begin{array}{c}\text { Standardized } \\
\text { Coefficients } \\
\text { Beta }\end{array}$} & \multirow[t]{2}{*}{$\mathrm{t}$} & \multirow[t]{2}{*}{ Sig. } \\
\hline & & $\mathrm{B}$ & Std. Error & & & \\
\hline \multirow{3}{*}{1} & (Constant) & .432 & .212 & & 2.041 & .044 \\
\hline & Promosi & -.047 & .059 & -.091 & -.791 & .431 \\
\hline & Kualitas pelayanan & .090 & .063 & .164 & 1.420 & .159 \\
\hline
\end{tabular}

Sumber : data diolah, 2020

\section{Analisis Regresi Linear Berganda}

Model analisis regresi linear berganda digunakan untuk mendapat koefisien regresi yang akan menentukan apakah hipotesis yang dibuat akan diterima atau ditolak. Hasil analisis ini mengacu pada hasil pengaruh variabel Promosi $\left(\mathrm{X}_{1}\right)$, variabel Kualitas pelayanan $\left(\mathrm{X}_{2}\right)$ terhadap Kepuasan pelanggan (Y) Pengguna Jasa Transportasi Online Grab di Denpasar.

Tabel 9. Hasil Analisis Regresi Linear Berganda Coefficients $^{\mathrm{a}}$

\begin{tabular}{|c|c|c|c|c|c|c|}
\hline \multirow{2}{*}{\multicolumn{2}{|c|}{ Model }} & \multicolumn{2}{|c|}{$\begin{array}{c}\text { Unstandardized } \\
\text { Coefficients }\end{array}$} & \multirow{2}{*}{$\begin{array}{c}\begin{array}{c}\text { Standardized } \\
\text { Coefficients }\end{array} \\
\text { Beta } \\
\end{array}$} & \multirow[t]{2}{*}{$\mathrm{t}$} & \multirow[t]{2}{*}{ Sig. } \\
\hline & & $\mathrm{B}$ & Std. Error & & & \\
\hline \multirow{3}{*}{1} & (Constant) & .093 & .359 & & .259 & .796 \\
\hline & Promosi & 699 & .100 & .583 & 6.981 & .000 \\
\hline & Kualitas pelayanan & .243 & .107 & .190 & 2.268 & .026 \\
\hline
\end{tabular}

Sumber : data diolah, 2020

Berdasarkan Tabel 9 dapat ditulis persamaan regresi linear berganda menjadi $\mathrm{Y}=$ $0,093+0,699 X_{1}+0,243 X_{2}$. Persamaan regresi linear berganda tersebut dapat diuraikan sebagai berikut : 
Nilai constant 0,093 menunjukan apabila Promosi, Kualitas pelayanan, bernilai sama dengan 0 (nol) maka Kepuasan pelangganPengguna Jasa Transportasi Online Grab di Denpasar bernilai sebesar 0,093

$\mathrm{X}_{1}=+0,699$ menunjukkan bahwa Promosi berpengaruh positif terhadap Kepuasan pelangganPengguna Jasa Transportasi Online Grab di Denpasar, apabila Promosi meningkat maka Kepuasan pelangganakan mengalami peningkatan sebesar 0,699.

$\mathrm{X}_{2}=+0,243$, menunjukkan bahwa Kualitas pelayananberpengaruh positif terhadap Kepuasan pelangganPengguna Jasa Transportasi Online Grab di Denpasar, apabila Kualitas pelayanan meningkat maka Kepuasan pelangganakan mengalami peningkatan sebesar 0,243 .

Berdasarkan Tabel 9 maka dapat dikemukakan hasil uji terhadap hipotesis $1(\mathrm{H} 1)$ dan hipotesis 2 (H2) yang masing-masing menyatakan promosi dan kualitas pelayanan berpengaruh positif dan signifikan terhadap kepuasan pengguna jasa transportasi online Grab di Denpasar sebagai berikut :

1. Pengaruh Promosi terhadap Kepuasan pelanggan diperoleh $t_{\text {hitung }}(6,981)>t_{\text {tabel }}$ $(1,985)$ dengan tingkat signifikansi $0,000<0,05$, sehingga $\mathrm{H}_{0}$ ditolak dan $\mathrm{H}_{\mathrm{a}}$ diterima yang berarti bahwa variabel Promosi berpengaruh positif signifikan terhadap Kepuasan pelanggan. Koefisien regresi $\beta 1$ (variabel Promosi) sebesar 0,699, menunjukkan bahwa dengan meningkatnya Promosi yang terdapat Pengguna Jasa Transportasi Online Grab di Denpasar maka akan meningkatkan Kepuasan pelanggan Pengguna Jasa Transportasi Online Grab di Denpasar. Hasil penelitian ini juga sesuai dengan hasil penelitian oleh Soni Suntani Sentiana (2018) yaitu promosi berpengaruh positif dan signifikan terhadp kepuasan pelanggan restoran dikawasan lembang.

2. Pengaruh Kualitas pelayanan terhadap Kepuasan pelanggan diperoleh $t_{\text {hitung }}(2,268)>$ $t_{\text {tabel }}(1,985)$ dengan tingkat signifikansi $0,026<0,05$, sehingga $\mathrm{H}_{0}$ ditolak dan $\mathrm{H}_{\mathrm{a}}$ diterima yang berarti bahwa variabel Kualitas pelayanan berpengaruh positif signifikan terhadap Kepuasan pelanggan . Koefisien regresi $\beta 2$ (variabel Kualitas pelayanan) sebesar 0,243, menunjukkan bahwa meningkatnya Kualitas pelayanan maka akan meningkatkan Kepuasan pelanggan Pengguna Jasa Transportasi Online Grab di Denpasar. Sesuai dengan hasil penelitian dari Endang Tjahningsih (2013) yang menyatakan bahwa promosi bahwa berpengaruh positif terhadap kepuasan pelanggan supermarket Carrefour di semarang. 


\section{Uji Signifikansi Simultan (Uji F)}

Uji F digunakan untuk mengetahui apakah secara serempak (simultan) seluruh variabel bebas memiliki pengaruh terhadap variabel terikat.

\begin{tabular}{lrrrrr}
\multicolumn{8}{c}{ Tabel 10. Hasil Uji F } \\
ANOVA $^{\mathbf{a}}$
\end{tabular}

Sumber : data diolah, 2020

Berdasarkan uji F ( secara Simultan ) dperoleh $F_{\text {hitung }}(45,546)>F_{\text {tabel }}(3,09)$ dengan nilai signifikansi $\mathrm{F}$ adalah $0,000<0,05$, maka $\mathrm{H}_{0}$ ditolak. Hal ini berarti bahwa variabel Promosi $\left(\mathrm{X}_{1}\right)$, variable Kualitas pelayanan $\left(\mathrm{X}_{2}\right)$, secara simultan berpengaruh secara signifikan terhadap Kepuasan pelanggan (Y) Pengguna Jasa Transportasi Online Grab di Denpasar, dengan nilai $\mathrm{R}^{2}=48,4$ persen, yang berarti bahwa sebesar 48,4 persen Kepuasan pelanggan Pengguna Jasa Transportasi Online Grab di Denpasar dipengaruhi oleh variabel Promosi $\left(\mathrm{X}_{1}\right)$,Kualitas pelayanan $\left(\mathrm{X}_{2}\right)$, dan sisanya sebesar 51,6 persen dipengaruhi oleh variabel lain yang tidak diteliti pada penelitian ini Hasil penelitian ini sejalan dengan penelitian oleh Bagus Handoko ( 2017) yang menyatakan bahwa promosi berpengaruh positif dan signifikan terhadap kepuasan konsumen, kualitas berpengaruh positif dan signifikan terhadap kepusan konsumen.

\section{Penutup}

\section{Simpulan}

Berdasarkan hasil analisis data dan pembahasan, maka didapat simpulan hasil penelitian adalah sebagai berikut :

1. Promosi berpengaruh positif dan signifikan secara parsial terhadap Kepuasan pelanggan Pengguna Jasa Transportasi Online Grab di Denpasar.

2. Kualitas pelayanan berpengaruh positif dan signifikan secara parsial terhadap Kepuasan pelanggan Pengguna Jasa Transportasi Online Grab di Denpasar.

3. Berdasarkan hasil penelitian, ditemukan bahwa Promosi serta Kualitas pelayanan berpengaruh signifikan secara simultan terhadap Kepuasan pelanggan Pengguna Jasa Transportasi Online Grab di Denpasar. 


\section{Saran}

Dalam usaha meningkatkan Kepuasan pelanggan maka disarankan Pada sebagai berikut :

1. Dalam upaya untuk memperhatikan Promosi harus memperhatikan Promosi yang terdapat di Transportasi Online Grab, dengan Promosi yang menarik maka dapat meningkatkan Kepuasan pelangganPengguna Jasa Transportasi Online Grab di Denpasar, hal yang harus ditingkatkan adalah indikator yang memiliki rata-rata terendah yaitu Grab memberikan reward untuk pelanggan setia sebagai bentuk apresiasi berupa pelayanan gratis, berarti Jasa Transportasi Online Grab harus memberikan apresiasi kepada pelanggannya berupa pelayanan gratis, agar pelanggan grab merasa puas dan akan menggunakan Jasa Transportasi Online Grab kembali

2. Transportasi Online Grab perlu lebih memperhatikan Kualitas pelayanan yang, dengan meningkatkan kualitas pelayanan Transportasi Online Grab, maka Kepuasan pelanggan Pengguna Jasa Transportasi Online Grab di Denpasar pun akan meningkat. Hal yang harus dilakukan adalah meningkatkan indikator yang memiliki nilai indikator yang terendah yaitu Saya memberikan peringkat yang baik untuk pelayanan driver Grab, kualitas pelayanan harus sangat diperhatikan, hal ini bisa di tingkatkan dengan cara perekrutan driver secara ketat, agar kualitas pelayanan dari Jasa Transportasi Online Grab bisa dipertahankan atau lebih ditingkatkan

3. Bagi penelitian selanjutnya diharapkan mampu menambah variabel- variabel yang dapat mempengaruhi Kepuasan pelanggan, mampu untuk menambahkan satu atau dua variabel intervening, serta mampu untuk memperluas ruang lingkup penelitian yang tidak hanya terbatas Pengguna Jasa Transportasi Online Grab di Denpasar atau dapat juga mengganti lokasi penelitian yang tidak hanya terfokus pada suatu lokasi penelitian, sehingga memberikan suatu pandangan yang lebih dan mampu diimplementasikan secara umum.

\section{Referensi}

Adnyana dan Suprapti, (2018), Pengaruh Kualitas Pelayanan Dan Persepsi Harga Terhadap Kepuasan Dan Loyalitas Pelanggan Gojek di Kota Denpasar. E-Jurnal Manajemen Unud, Vol. 7, No. 11, 2018: 6041 - 6069.

Assauri, Sofyan, (2014) Manajemen Pemasaran (Dasar, Konsep dan Strategi).

Badan Pusat Statistik. 2019.www.bps.go.id . (Diakses 10 oktoberber 2019).

Ghozali, Imam. 2011. Partial least squares konsep, Metode dan AplikasiMenggunakan Porgram Warp PLS 4.0. Semarang. 
Handoko, (2017), Pengaruh Promosi, Harga DanKualitas Pelayanan Terhadap Kepuasan Konsumen Pada Titipan Kilat JNE Medan

Hardiyansyah. 2011. Kualitas Pelayanan Publik, Konsep, Dimensi, Indikator, danImplementasinya. Yogyakarta: Gava Media.

Juniantara dan Sukawati, (2018), Pengaruh Persepsi Harga, Promosi, Dan Kualitas Pelayanan Terhadap Kepuasan Dan Dampaknya Terhadap Loyalitas Konsumen. EJurnal Manajemen Unud, Vol. 7, No. 11, 2018: 5955 - 5982

Kotler, Philip dan Amstrong. 2000. Prinsip-prinsip Pemasaran. Jakarta: PT Prenhallindo.

Kotler, Philip. 2005. Manajemen Pemasaran. Edisi Millenium Jilid Pertama. Jakarta: Prenhallindo.

Kotler, Philip dan Kevin Lane Keller. 2009. Manajemen Pemasaran (EdisiKetigabelas). Jakarta: Erlangga.Alma.

Kotler, Philip \& Keller. 2013. Manajemen Pemasaran. Edisi 12. Jilid 1. Alih Bahasa:Benyamin Molan. Indeks. Jakarta.

Sentiana, (2018), Pengaruh Harga dan Promosi Terhadap Kepuasan Pelanggan Serta Dampaknya Terhadap Loyalitas Pelanggan

Sugiyono. 2017. Metode Penelitian Kuantitatif, Kualitatif, dan R\&D. Bandung: Alfabeta.

Tjahjaningsih, (2013), Pengaruh Citra dan Promosi Terhadap Kepuasan Pelanggan Serta Dampaknya Terhadap Loyalitas Pelanggan.

Tjiptono,Fandy. 2004. Pemasaran Jasa. Malang: Bayu Media Publishing.

Tjiptono,Fandy. 2008. Strategi Bisnis Pemasaran. Yogyakarta: Penerbit Andi.

Wijaya Cynthia Violita, (2017), Pengaruh Kualitas Pelayanan Dan Kualita Produk Terhadap Kepuasan Konsumen Depot Madiun Masakan Khas Bu Rudy. AGORA, Vol. 5, No. 1. 